\title{
Sharing, Giving or Reselling: An Economic Analysis
}

\author{
Huihui Chi*, Wei Zhou ${ }^{\dagger}$ \\ *Information \& Operations Management Department, ESCP Europe, Paris, France \\ huihui.chi@edu.escpeurope.eu \\ $\dagger$ Information \& Operations Management Department, ESCP Europe, Paris, France \\ wzhou@escpeurope.eu
}

\begin{abstract}
We consider the non-linear properties and boundaries in the three forms of sharing, gift, and reselling economy. We decode the economic rationality and marketplace mechanisms in today's ever booming sharing/gifting/reselling networks. We contribute to the fundamental economics literature by decomposing a merchandise into two parts: the ownership good and the detached good. The ownership good can be utilized or shared by the owner. The detached good can either be given as a gift or be resold for an income. The separation is bounded by considering the estimated finite life of the good and a future time stamp of detachment. We consider owner's holding cost, various transaction costs, rewards, as well as the incentive mechanism from the network. We find that there exist various conditions when certain ownership form is more preferred to the others. Our results also indicate that governmental and marketplaces' incentive policies play an important role when consumers make decisions among the three economic forms and consequently adjusting the total social welfare.
\end{abstract}

Keywords: Gift Economy, Sharing Economy, Resale Market, Incentive Policy

\section{INTRODUCTION}

Thanks to the fast development of information technology, the Internet based social networks and online marketplace, the economies of sharing, gifting, and reselling have emerged as important elements in our daily lives. The sharing economy refers to the economic activities when goods or services are arranged to be shared among a group of consumers, characterized by a discounted. The Gift economy refers to the economic activities that aim to transfer goods or services freely to other individuals without an agreed method of quid pro quo. The economy of reselling represents the transfer of the remaining value of goods accompanied by a resale price.
Before the end of life time stamp of a good or service, the owner has the free choice to use, share, give, or sell its remaining value. For examples, the old clothes, the unused instruments, a used car, an apartment, their value can be realized by various economic forms. What affects an owner's decision to choose one form that makes the best economic sense? There are several important elements that we must consider: including the value of the goods, inventory cost, transaction costs, policy incentives and available marketplaces.

A costly inventory would normally give the owner a strong incentive to detach the good's ownership by resale or gift-giving. On the contrary, a high remaining value of the good would make the owner willing to keep the ownership for individual or group consumption. In this research, we are motivated to investigate the impact of these key elements on sharing/gift/resale decisions and the balance/equilibrium among these three forms in economics.

Today's sharing economy is usually carried out on a networked platform that allows people to share goods and services. In recent years, many sharing marketplaces have emerged, targeting various economic segments, for example AirBnB and Roomorama for lodgement, SnapGoods for tools, RelayRides for cars, Wheelz for bikes, Uber and Lyft for ad hoc taxi services, etc. Services can also be shared, for example peer-to-peer lending, crowdfunding, and couchsurfing, coworking, knowledge and talent-sharing, etc. The sharing economy is characterized by group consumption, which means cheaper, extra income for the owners, and a new social-networked communities. We foresee that sharing economy will keep evolving and become more flexibility and eminent in the near future because of its fundamental economic drives.

To some extent, sharing sounds like rental which is a classic form of economy because under both circumstances, the owner of the good makes money by transferring the right to use it without changing 
the ownership of the good. However, there are some differences between sharing and rental. First of all, sharing economy is more like a group behavior while rental is an individual behavior. For example, the users of Uber who do not know each other may take one car to the same destination for saving the cost and time, but renting a car usually means only the lessee could use the car during the tenancy term no matter how he uses it. Secondly, the owner could use the good with others at the same time in sharing economy while that would not happen in rental economy. For instance, the users of AirBnB might find a room on the website which needs to live with the owner of the house, but renting a house always means renting the whole house and a formal lease contract is provided. To summarize, sharing economy is more flexible and convenient than rental while the rental is more standard and traditional, so people choose sharing or rental according to their different demands and purposes.

Gift economy is a method for people to transfer goods or services without any payoff of exchange. Nowadays, applications based on the gift economy principles varies widely. For example, we have the charitable donation, collectivism, cooperativeness, donation requested, pay as you will, pay it forward, and proceeds of sale donated. The gift economy represents an optimistic attitudes of people and it's like a way to transfer the goods or services form relative abundance to relative scarcity. What's more, it's motivated by people's compassion, generosity and favor the common good over individual advantages. However, another important perspective forces us to review and reflect on how we think about and measure value. This awareness can be transferred into normal market transactions as well, taking the indirect costs like inventory costs and profits of specific acts of material consumption into consideration.

Resale marketplace is another option that the owner can seek in order to transfer the ownership of the goods/services. Because of the lack of pricing structure of un-uniform resale market, auction is often used in order to retrieve the genuine value of the goods in demand, for example eBay. Fixed price or negotiation are also common, for example Amazon marketplace. The transaction cost can be very high and the value can be underestimated due to the lack of standardized pricing structure in the resale market.

The goods that are idle for one person may be needed by others, so they can make a deal by sharing, giving, or reselling. During the ownership period, we make a simplified definition by considering individual consumption as a special case of collective consumption when only the owner utilizes the good/service. By considering all the factors that influence the decision making, with general rationality, the owner is more willing to keep the ownership when the future income and the value exceeds the costs of holding it. When the holding cost is significantly high, the owner would be more likely to transfer the ownership. There should exists an equilibrium where the owner is indifferent of sharing, giving, or reselling. The indifference point is further adjustable by the sharing network, charity organizations, the taxation policy, and by resale marketplace.

Among all the above mentioned factors, inventory cost is one of the most significant one because it accumulates over time. The rest of the factors/costs are mostly static at a certain time point. By assuming a limited life of product, we thus are keen to investigate the impact of the cost structure and incentive mechanisms that are offered by the three economic forms. Among the three, gift economy is rarely studied because of lack of incentives. We argue that besides the psychological causes to give gift, the economic benefit is also a vital motivation for owners to give goods for free. It could simply be the high accumulative inventory cost or the strong taxation incentive.

In this research, we aim to investigate the interchangeable relationships among the seemingly unrelated sharing, gift and resale economy. We contribute to both the economics and IS literature by identifying the most important drives of the three economic forms, including the inventory holding cost, the transaction costs, the financial incentives, and the various time stamps. Moreover, we base our analysis on two variations of substitute modeling and consider the properties of social welfare by incorporation the utility functions of different players. As a result, we show that both individual utility and total social welfare are augment-able by fine-tuning the the incentives, the transaction costs, and eventually the time of ownership transfer of the goods. Our results bring meaningful and interesting insights to today's sharing, gift, and resale platform companies on how to improve the efficiency and competitiveness.

The remainder of this paper is organized as follows. In section II, We provide a brief review of literature in sharing economy, gift economy and resale market. 
In Section III we propose an economic model that is able to describe and differentiate these three economic forms. We discuss the results and draw managerial implication in Section IV. We make concluding remarks and give guidance to future research in Section V.

\section{Literature Review}

From the existing literature in sharing economy, gift economy and resale market, we find a common agreement that all forms of ownership must create real consumer value at the end. The concept of sharing bikes( Wheelz), cars(Uber), or houses(Airbnb) begins to become more and more popular [5]. In order to obtain the stable mobility, existing shared mobility business models try hard to find the optimal relationship between good owners and receivers. What's more, sharing economy now achieves success in the competition with concrete firms and makes itself differential to acquire market share [14]. The economy of sharing is often linked to the collaborative consumption [2]. In terms of how we think about ownership, collaborative consumption is often considered as important as the Industrial Revolution. Almost all industries are involved in this ongoing disruptive change of sharing economy and collaborative consumption. People can use collaborative consumption as a force to effect the sustainable development and a method to strengthen communities [3]. On the top of that, owing to information and communications technologies, collaborative consumption develops rapidly [7]. And different factors like sustainability play important roles in motivating the participation in CC.

However, its dark side need to be deal with when the sharing economy grows up [8], which means to gain unfair advantage like regulatory arbitrage should be avoided. And democratizing the ownership and governance of the platform would help to control the power of new technologies [12]. In the other hand, there are still fleet and inventory cost even in the sharing economy[13]. New sharing economy market like reengineered consumption models are needed.

Supposing if there is no inventory cost, the owner of the goods/services would have the intention to keep them with any residue value. If there exist a reward to transfer the ownership as a gift or certain holding cost, the tendency to keep the goods may withdraw. It creates the economy of gifts. With non-zero inventory cost, depreciating value of the good,and taxation benefit, the owner might make a negative utility if he/she holds the good. The gift economy, however, is not always attractive [9], and it can push people away and seek the valorized market as an alternative option. What's more, people pay little attention and hardly show their understanding to gift giving [4], because of the privacy and conceptual framework of this activity.

Resale market heavily depreciated machines produced in these dispute-affected equipment [10]. Besides, components of these machines were resold more frequently and received lower list prices. In standard auctions, there is a bidder in resale market who doesn't have any use value for the good on sale [6]. When resale leads the auction, there is an equilibrium in the auction-plus-resale game, which would determine the bidding price [1]. But in perfect resale market, the auction with resale would not be the best choice for the seller.

\section{Substitution Model of Sharing, Giving, \& RESELLing}

Thanks to the fast development of the Internet, the IoT technologies and the social networks, the barrier of collaborative trade, consumption, and donation become much smaller comparing to that in the recent past. It creates new but significantly large business communities of sharing, giving and reselling goods and services. We are keen to firstly investigate the relationship among these emerging economic forms and secondly to probe their boundaries as well as the optimal choices when the best social/individual welfare is extracted.

We observe certain similarities among the three forms by considering the time when the good's ownership is transferred. Individual and collaborative consumption is characterized by holding the ownership. Well, collaborative consumption does not strictly follow the ownership if the consumer only "rent". Because the focus of this research is on the boundary of sharing and gift, we emphasize on the good owner's decision in the following model development. Gift and resale are similar because in both forms the ownership will be transferred. Figure1 demonstrate how we can decompose a good or service simply based on its expected life and the time point of ownership transfer.

A good can be decomposed into two parts by specifying the separation point when the ownership is transferred on the time line, which ranges from time zero to its end of life (Figure 1). Let $\mathrm{T}$ represent the end of life time stamp of a good. We decompose the good/service in two parts: the ownership part $\left(P_{s}\right)$ and the detachment part $\left(P_{g}\right.$ or $\left.P_{r}\right) . P_{g}$ represents 


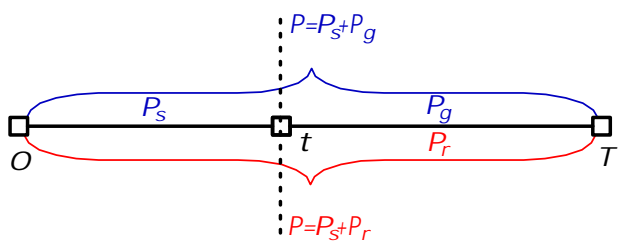

Fig. 1. Decomposition of a good

the remaining part to be given as a gift and $P_{r}$ indicates that the remaining value will be resold on a reselling market. Whenever the good still belongs to the owner, he/she has to choose whether to separate the ownership in the future, when $(t)$, and how (gift or resale).

We need to compare the utility of sharing and giving and reselling. Because of the difference in ownership and accumulative effect of time, sharing needs considering more concerns than giving rather than making the decision only according to the value at a certain time. Furthermore, if the owner decides to give up the ownership, the choice between the giving and reselling depends on the payoff of the two choices. To be specific, the value of reward, the price of reselling and transaction costs are the key factors to affect the payoffs.

\section{A. The Incentive 8 Cost Structure}

The gift economy is different from a free supplydemand market because the goods are not well organized, listed and marketed to the consumers. It involves transaction costs for both donors and receivers to give and find the right goods. In this sense, the intermediary plays a very important role in reducing the transaction costs from both side by giving effort to improve the service.

We consider the intrinsic value of goods, inventory holding cost, transaction cost, and good-will rewards in the gift economy model.

We use the following list of notations:

- $V$ : value of the good

- $H C$ : holding cost of the good

- $R(v)$ : Good-will reward of giving a gift

- $S$ : Income from sharing

- $T C_{1}$ : Transaction cost of sharing

- $T C_{2}$ : Transaction cost of gift

- $T C_{3}$ : Transaction cost of resale

- $T$ : estimated remaining life of the good from time zero
- $\operatorname{Re}(v)$ : Resale price

- $i$ : time interest/discount rate

- $U_{r}$ : Utility from resale

- $U_{g}$ : Utility from gift giving

- $U_{1}$ : Utility from owning the good

- $U_{2}$ : Utility from detaching the good

At any time point of a good before its end of life, the owner has three choices: 1) to give the good as a gift, or 2) to share(use) it, 3) to resell it. The utility of sharing/using the good is the value of the good $(V)$ plus the income from sharing/using it $(S)$ minus the holding/maintenance cost $(H C)$ and the transaction cost $\left(T C_{1}\right)$ as represented in (1). The utility of gift giving consists of the inventory holding credit $(H C)$ plus the reward $(R)$ minus the value of the good $(V)$ and the transaction $\operatorname{cost}\left(T C_{2}\right)$, equation (2). The utility of reselling the good is price of the good according to the value of the good $(V)$ minus the holding/maintenance cost $(H C)$ and the transaction $\operatorname{cost}\left(T C_{3}\right)$ as represented in (4)

$$
\begin{aligned}
& U_{1}=V(t)-H C(t)-T C_{1}+S(t) \\
& U_{2}(t)=\operatorname{Max}\left\{U_{g}, U_{r}\right\}_{t} \\
& U_{g}=H C(t)-V(t)-T C_{2}+R \\
& U_{r}=\operatorname{Re}(V(t))+H C(t)-V(t)-T C_{3}
\end{aligned}
$$

Equation (1) to (4) depict the economical rationality behind sharing/gift/resale decision in general. We can further define the product valuation, the holding cost, and the sharing income according to time as follows:

$$
\begin{aligned}
& V(t)=A\left(\frac{e^{k}}{1+i}\right)^{t} \\
& H C(t)=\frac{C}{\ln (1+i)}\left[1-(1+i)^{-t}\right] \\
& S(t)=s \cdot t
\end{aligned}
$$

In equation (5), $k$ is the a kind of value power which shows the change of value. value decreases with the time when $k<0$ while value increases when $k>0$. In the (6), we assume unit holding cost is a constant, maintenance cost. In the (7), we assume unit sharing income is a constant like monthly or weekly rental income. Equation (5) to (7) are still very general, and can be fine-tuned according to commodity types in different industries or applications. We use these 
equations to facilitate the calculations and to demonstrate the boundaries and conditions in the different economic forms.

Theorem 1. At any time point if $\alpha=\operatorname{Re}(V(t))-$ $T C_{3}+T C_{2}-R>0$, resale is more preferable than gift giving. Otherwise, the good owner would rather like to make a donation.

Proof. It can be easily proved by comparing $U_{r}$ with $U_{g}$ where $\alpha$ stands for the difference between these two possible owner's utilities.

From now on we use $U_{2}$ to represent the utility of detaching the good, where $U_{2}(t)=\operatorname{Max}\left\{U_{g}, U_{r}\right\}_{t}$. If we consider $U_{1}$ and $U_{2}$ as two substitute choices for the owner, which means if $U_{1}$ surpasses $U_{2}$, the owner intends to share. Otherwise, if $U_{2}$ is greater than $U_{1}$, he/she prefer to detaching the good either as a gift or as a resale item. His/Her maximization problem for perfect complements can be modeled as follow:

$$
\operatorname{Max} U\{x, y\}_{t}
$$

subject to:

$$
\begin{aligned}
& x_{t} U_{1}+y_{t} U_{2}=U\{x, y\}_{t} \\
& x_{t}+y_{t}=1 \\
& x_{t} \in\{0,1\} \\
& y_{t} \in\{0,1\}
\end{aligned}
$$

From equations (5) to (7), We can form the following intermediate formulas regarding the remaining value of the good, the inventory cost/credit, and the sharing income.

$$
\begin{aligned}
& V(t)^{\prime}=A\left(\frac{e^{k}}{1+i}\right)^{t}[k-\ln (1+i)] \\
& V(t)^{\prime \prime}=A\left(\frac{e^{k}}{1+i}\right)^{t}[k-\ln (1+i)]^{2} \\
& H C(t)^{\prime}=C(1+i)^{-t} \\
& H C(t)^{\prime \prime}=-C \ln (1+i)(1+i)^{-t} \\
& S^{\prime}=s \\
& S^{\prime \prime}=0
\end{aligned}
$$

and draw the graph of $U_{1}$ and $U_{2}$ respectively in the same coordinate system in order to determine whether $x=1$ or $y=1$. alternatively, we can also observe the function $U_{1}-U_{2}$ directly to find the even point.
To be detailed:

$$
\begin{aligned}
& U_{1}(t)^{\prime}=V^{\prime}-H C^{\prime}+S^{\prime} \\
& U_{1}(t)^{\prime \prime}=V^{\prime \prime}-H C^{\prime \prime}+S^{\prime \prime} \\
& U_{1}(0)=A-T C_{1} \\
& U_{2}(t)^{\prime}=H C^{\prime}-V^{\prime} \\
& U_{2}(t)^{\prime \prime}=H C^{\prime \prime}-V^{\prime \prime} \\
& U_{2}(0)=-A+R-T C_{2}
\end{aligned}
$$

Theorem 2. If $k>\ln (1+i)$, the owner would be more likely to prefer to sharing/holding the good than giving it out as a gift.

Proof. Because the value of the good always increases, the owner would consider keeping the ownership of the good as appreciation instead of depreciation.

So we will discuss under the circumstance $k<$ $\ln (1+i)$, which makes $V^{\prime}-H C^{\prime}=A[k-\ln (1+$ i) $]\left(\frac{e^{k}}{1+i}\right)^{t}-C(1+i)^{-t}$ lower than zero in that case. What's more, it's obvious to get that $U_{2}(t)^{\prime}>0$ and $U_{2}(t)^{\prime \prime}<0$ while $U_{1}(t)^{\prime \prime}>0$. And there are two situations for the sign of $U_{1}(t)^{\prime}$. However, $U_{1}(\infty)^{\prime}=$ $S^{\prime}>0$ shows that no matter whether the initial value $U_{1}(t)^{\prime}$ is positive or negative, $U_{1}(t)^{\prime}$ would become positive eventually. So we could draw different graphs for different $U_{1}(0)^{\prime}$. Last but not least, it's worthy to compare $U_{1}(0)$ and $U_{2}(0)$. The specific situations will be demonstrated in the following theorems.

Theorem 3. if $U_{1}(0)>U_{2}(0)$ and $U_{1}(0)^{\prime}>0$, then $U_{1}(t)$ always exceeds $U_{2}(t)$, which means the owner will share the good until the end of product life cycle.

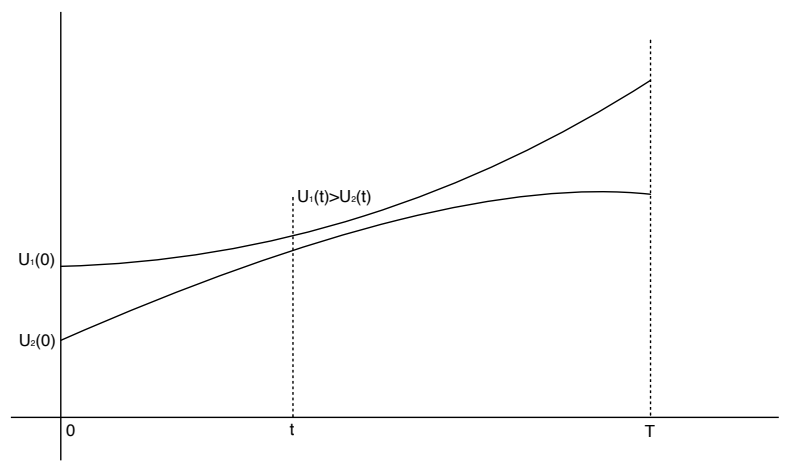

Fig. 2. A1

Proof. Because $U_{1}(0)^{\prime}>0, U_{1}(t)^{\prime \prime}>0, U_{1}(t)^{\prime}>0$, which indicates $U_{1}(t)$ monotonously increases. At the same time, $U_{2}(t)$ monotonously increases. From the 
perspective of $\left[U_{1}-U_{2}\right](t)$, we can get $\left[U_{1}-U_{2}\right](t)>$ $0,\left[U_{1}-U_{2}\right](0)^{\prime}>0,\left[U_{1}-U_{2}\right](t)^{\prime \prime}>0$ given those conditions, which result in $\left[U_{1}-U_{2}\right](t)>0$ is correct for all the $t$. In other words, $U_{1}(t)>U_{2}(t)$ is always correct.

Let $t_{0}$ satisfies that $U_{1}\left(t_{0}\right)^{\prime}=0$, and $t^{\star}$ is the first point which satisfies $U_{1}\left(t^{\star}\right)=U_{2}\left(t^{\star}\right)$ then:

Theorem 4. If $U_{1}(0)>U_{2}(0), U_{1}(0)^{\prime}<0$ and $t_{0}>T$, then the separation point of sharing and giving is $t^{\star}$, which means the owner will share the good until $t^{\star}$ and after $t^{\star}$, the owner will choose to give it as a gift.

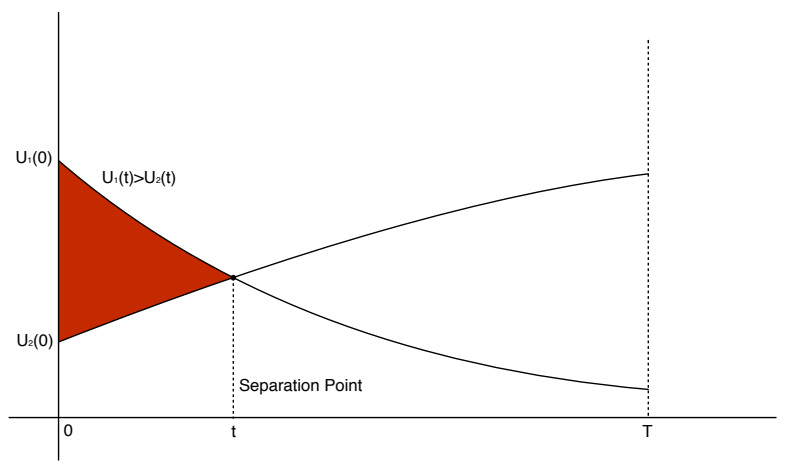

Fig. 3. A2

Proof. Because $U_{1}(t)^{\prime \prime}>0$ and $U_{1}(0)^{\prime}<0$, it's obvious to assure there exists a zero point $t_{0}$ of $U_{1}(t)^{\prime}$. And then, we can say that $U_{1}(t)$ decreases in $\left[0, t_{0}\right]$ and increases in $\left[t_{0}, \infty\right)$. In this case, $t_{0}>T$ indicates $U_{1}(t)$ monotonously decreases. In the other hand, $U_{2}(t)$ monotonously increases. As the result of $U_{1}(0)>U_{2}(0)$, if $U_{1}(T)<U_{2}(T)$, then there must be a intersection $t^{\star}$, otherwise $U_{1}(t)>U_{2}(t)$ is always true like former case.

Theorem 5. If $U_{1}(0)>U_{2}(0), U_{1}(0)^{\prime}<0$ and $t_{0}<T$, then $t^{\star}$ is the potential separation point, which means the owner will give the good away at the time $t^{\star}$ indeed if the grey area is larger than the second red area, otherwise the owner will share it until the $T$.

Proof. Because of the same analysis as former case and $t_{0}<T, U_{1}(t)$ decreases in $\left[0, t_{0}\right]$ and increases in $\left[t_{0}, \infty\right)$. As the result of $U_{1}(0)>U_{2}(0)$, if $U_{1}\left(t_{0}\right)<$ $U_{2}\left(t_{0}\right)$, then there are two intersections for us to consider, otherwise $U_{1}(t)>U_{2}(t)$. To be detailed, $t^{\star}$ is sure to be achieved and it's more important than the second one because $t^{\star}$ is potential giving point while

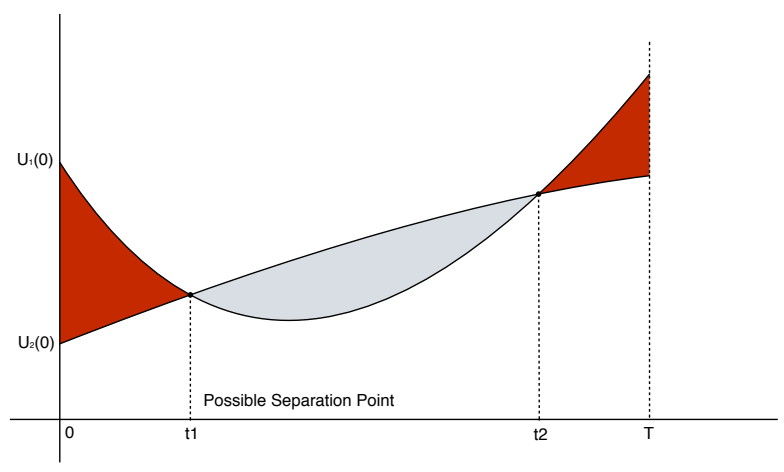

Fig. 4. A3

the second one is not. We just need it to determine whether to give the good at the time $t^{\star}$ by comparing the red area after the second intersection and the grey area before it. So actually, we don't care its existence and value.

Theorem 6. If $U_{1}(0)<U_{2}(0)$ and $U_{1}(0)^{\prime}>0$, then $t^{\star}$ is the potential separation point, which means the owner will give the good away at the time $t^{\star}$ indeed if the grey area is larger than the red area, otherwise the owner will share it until the $T$.

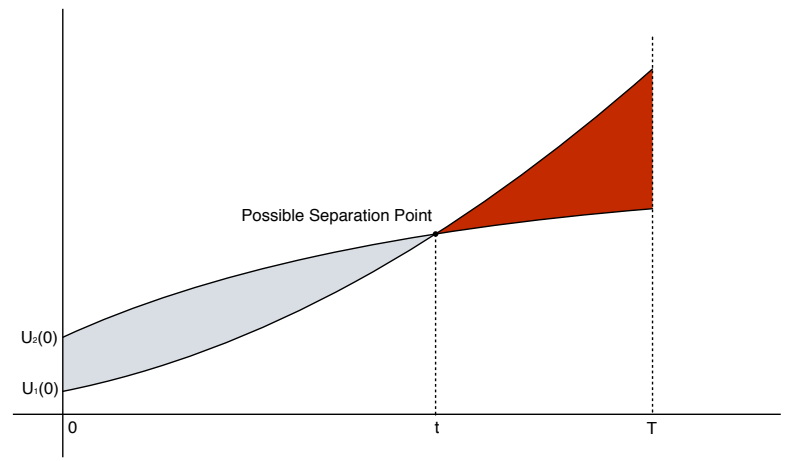

Fig. 5. B1

Proof. Because $U_{1}(0)^{\prime}>0, U_{1}(t)^{\prime \prime}>0, U_{1}(t)^{\prime}>$ 0 , which indicates $U_{1}(t)$ monotonously increases. At the same time, $U_{2}(t)$ also monotonously increases. However, $U_{1}(0)<U_{2}(0)$. So we need to discuss the function $\left[U_{1}-U_{2}\right](t)$. From the conditions, we get that $\left[U_{1}-U_{2}\right](0)<0,\left[U_{1}-U_{2}\right](t)^{\prime}>0$, which shows $\left[U_{1}-U_{2}\right](t)$ increases monotonously from a negative initial value. And the existence of $t^{\star}$ turns to be nature. 
Theorem 7. If $U_{1}(0)<U_{2}(0)$ and $U_{1}(0)^{\prime}<0$ then $U_{2}(t)$ always exceeds $U_{1}(t)$, which means the owner will give the good as a gift at the beginning.

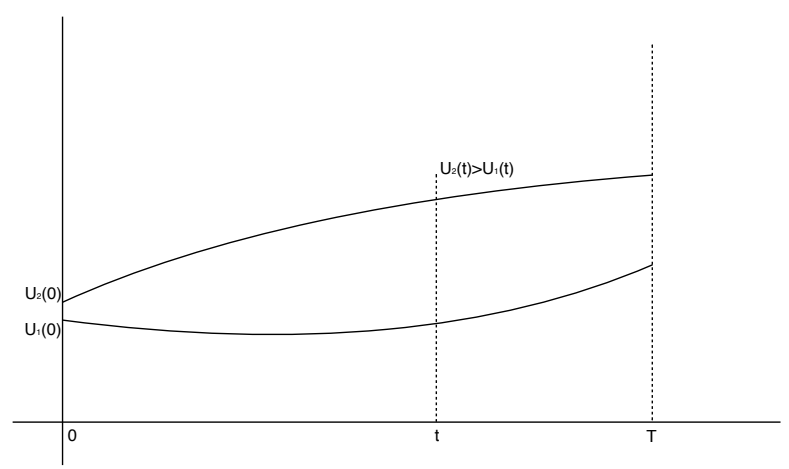

Fig. 6. Complete Gift Giving

Proof. In this case, $U_{1}(t)$ decreases in $\left[0, t_{0}\right]$ and increases in $\left[t_{0}, \infty\right)$ because of the condition $U_{1}(0)^{\prime}<0$, while the $U_{2}(t)$ monotonously increase. What's more, $U_{1}(0)<U_{2}(0)$ shows that before $t_{0}, U_{1}(t)<U_{2}(t)$ is always true. However, we can't deny there will be a $t^{\star}$ making $U_{1}\left(t^{\star}\right)=U_{2}\left(t^{\star}\right)$, but in most cases $t^{\star}$ would exceed $T$.

For the purpose of observing the process more clearly, we could consider the function $\left[U_{1}-U_{2}\right](t)=$ $2(V-H C)+S(t)-T C_{1}-R+T C_{2}$, which has the similar trend with $U_{1}(t)$. As for the inflection point for people from sharing to giving, the condition $U_{1}\left(t^{\star}\right)=$ $U_{2}\left(t^{\star}\right)$ is equivalent to the condition $\left[U_{1}-U_{2}\right]\left(t^{\star}\right)=0$.

From the graph of $U_{1}-U_{2}$, we can see when [ $U_{1}-$ $\left.U_{2}\right](0)>0$, if the minimum of the function is lower than 0 , it will exist $t^{\star}$, otherwise $U_{1}-U_{2}$ is always higher than 0 . To conclude, let $t_{1}$ satisfies that $\left[U_{1}-\right.$ $\left.U_{2}\right]\left(t_{1}\right)^{\prime}=0$, then only when $\left[U_{1}-U_{2}\right]\left(t_{1}\right)<0$, a $t^{\star}$ could be found. And it also can be observed from the graph that higher the value of $\left[U_{1}-U_{2}\right]\left(t_{1}\right)$, higher the value of $t^{\star}$. However, when $\left[U_{1}-U_{2}\right](0)<0$, potential $t^{\star}$ must exist but we need to determine whether to give the good at the beginning.

Theorem 8. let $\left[U_{1}-U_{2}\right](t)=2[V(t)-H C(t)]+$ $S(t)-T C_{1}+T C_{2}-R$, given that $t_{1}$ satisfies $2\left[V\left(t_{0}\right)^{\prime}-\right.$ $\left.H C\left(t_{0}\right)^{\prime}\right]+S^{\prime}=0$, then the increase in $\left[U_{1}-U_{2}\right]\left(t_{1}\right)$ would cause the increase in $t^{\star}$ and vice verso.

Proof. As mentioned above, the initial value of $\left[U_{1}-\right.$ $\left.U_{2}\right](t)$ is positive, and $\left[U_{1}-U_{2}\right](t)$ monotonously decreases when $t$ increases to $t_{1}$. As the result of that, less the value of $\left[U_{1}-U_{2}\right]\left(t_{1}\right)$, less the value of $t^{\star}$.

\section{B. An Alternative Model}

Because it's possible for the owner to share the good for a certain time period and give it as a gift in the future, we may consider $x$ and $y$ as the tendency of sharing and gift-giving respectively. In this case, we shall abandon constraints $(9)(10)(11)$ and make $x$ and $y$ continuous. In other words, we will take the two different statuses of a certain good, which are sharing and giving, as two competitors in order to find the result of the battle between sharing and giving.

If we consider the total remaining life of the good as $T$ and when the owner gives it as a gift in a future time point $t, x$ represents the proportion of sharing as $x=\frac{t}{T}$, and $y$ represents the proportion of giftgiving $y=1-x$. The original problem from (3) to (7) becomes:

$$
\operatorname{Max} U\{x, y\}
$$

subject to:

$$
\begin{aligned}
& x U_{1}(t)+y U_{2}(t)=U\{x, y\} \\
& x+y=1 \\
& x=\frac{t}{T}, \quad x \in[0,1] \\
& y=1-\frac{t}{T}, \quad y \in[0,1] \\
& t \leq T \\
& U_{1}(t)=V(t)-H C(t)+S(t)-T C_{1} \\
& U_{2}(t)=\operatorname{Max}\left\{U_{g}, U_{r}\right\}_{t}
\end{aligned}
$$

(5) states the intrinsic value of the good at a future time $t$ from time point 0 . In order to calculate $V_{j}$, we take into consideration of depreciation that consists of the initial value of the asset and its estimated "life". (6) represents the accumulated value of released inventory cost as an "inventory holding credit".

where

$$
\begin{aligned}
& V(t)=A\left(\frac{e^{k}}{1+i}\right)^{t} \\
& H C(t)=\frac{C}{\ln (1+i)}\left[1-(1+i)^{-t}\right] \\
& V(t)^{\prime}=A\left(\frac{e^{k}}{1+i}\right)^{t}[k-\ln (1+i)] \\
& H C(t)^{\prime}=C(1+i)^{-t}
\end{aligned}
$$

From the perspective of (27), $M R S=-1$, while from the perspective of the linear utility function (26), $\frac{M U_{x}}{M U_{y}}=-\frac{U_{2}}{U_{1}}$. As the result of principles in the microeconomics, $M R S=\frac{M U_{x}}{M U_{y}}$ indicates $U_{1}(t)=U_{2}(t)$ is the condition for the optimal solution, which is the 
same condition with what we discuss in the previous part.

What's more, for the purpose of maximizing the utility, we need to find the point $t^{\star}$ which makes $\frac{\partial U}{\partial t}\left(t^{\star}\right)=0$. We can simplify that $\frac{\partial U}{\partial t}=\frac{1}{T}\left[U_{1}-U_{2}\right]+$ $\frac{t}{T}\left[U_{1}^{\prime}-U_{2}^{\prime}\right]+U_{2}^{\prime}$. And it's easy to prove the solution of that equation is exactly $t^{\star}$.

\section{ECONOMic \& MANAgerial Implications}

In general as been observed from Figure 2, $P_{s}$ and $P_{g}$ is separable by $t^{\star}$, which could be affected by the gift rewards $R$ and sharing income $S$. The reward usually has something to do with tax deduction, while sharing income usually directly relates to cost and sharing platform.

TABLE I

Analysis of Decision Points of Various Situations

\begin{tabular}{ccccccccc}
\hline PAR & th2 & th3 & th3 & th & th5 & th6 & th7 & th7 \\
\hline $\mathrm{A}$ & 10 & 10 & 10 & 10 & 10 & 10 & 10 & 10 \\
$\mathrm{i}$ & 0.1 & 0.1 & 0.1 & 0.1 & 0.1 & 0.1 & 0.1 & 0.1 \\
$\mathrm{k}$ & 0.1 & 0.09 & 0.09 & 0.09 & 0.09 & 0.09 & 0.09 & 0.09 \\
$\mathrm{C}$ & 0.1 & 0.1 & 1 & 1 & 1 & 0.1 & 1 & 1 \\
$\mathrm{~s}$ & 0.5 & 0.5 & 0.5 & 0.1 & 0.3 & 0.5 & 0.5 & 1.2 \\
$\mathrm{R}$ & 5 & 5 & 5 & 5 & 9 & 16 & 16 & 16 \\
$T C_{1}$ & 1 & 1 & 1 & 1 & 1 & 6 & 6 & 6 \\
$T C_{2}$ & 2 & 2 & 2 & 2 & 2 & 1 & 1 & 1 \\
$\mathrm{~T}$ & 20 & 20 & 20 & 20 & 20 & 20 & 20 & 20 \\
\hline$U_{1}(0)$ & 9 & 9 & 9 & 9 & 9 & 4 & 4 & 4 \\
$U_{2}(0)$ & -7 & -7 & -7 & -7 & -3 & 5 & 5 & 5 \\
$\partial U_{1}(0)$ & 0.45 & 0.35 & -0.55 & -0.95 & -0.75 & 0.35 & -0.55 & 0.15 \\
\hline$t_{0}$ & $\mathrm{NA}$ & $\mathrm{NA}$ & 8.4 & 30 & 14.5 & $\mathrm{NA}$ & 15.6 & 5.8 \\
$t^{*}$ & $\mathrm{NA}$ & $\mathrm{NA}$ & $\mathrm{NA}$ & 15 & 12.2 & 4.3 & 53.6 & 15.8 \\
\hline
\end{tabular}

The impact from the sharing income is that if only $S^{\prime}$ increases, then $t_{1}$ decreases, $\left[U_{1}-U_{2}\right]\left(t_{1}\right)$ decreases and $t^{\star}$ increases finally, even making giving not to happen as shown in the tabel II.

TABLE II

Analysis of Decision Points of Various $S^{\prime}$

\begin{tabular}{ccccccccc}
\hline PAR & th2 & th3 & th3 & th & th5 & th6 & th7 & th7 \\
\hline $\mathrm{A}$ & 10 & 10 & 10 & 10 & 10 & 10 & 10 & 10 \\
$\mathrm{i}$ & 0.1 & 0.1 & 0.1 & 0.1 & 0.1 & 0.1 & 0.1 & 0.1 \\
$\mathrm{k}$ & 0.99 & 0.09 & 0.09 & 0.09 & 0.09 & 0.09 & 0.09 & 0.09 \\
$\mathrm{C}$ & 1 & 1 & 1 & 1 & 1 & 1 & 1 & 1 \\
$\mathrm{~s}$ & 0.1 & 0.2 & 0.3 & 0.4 & 0.5 & 0.6 & 0.7 & 0.8 \\
$\mathrm{R}$ & 10 & 10 & 10 & 10 & 10 & 10 & 10 & 10 \\
$T C_{1}$ & 6 & 6 & 6 & 6 & 6 & 6 & 6 & 6 \\
$T C_{2}$ & 1 & 1 & 1 & 1 & 1 & 1 & 1 & 1 \\
$\mathrm{~T}$ & 20 & 20 & 20 & 20 & 20 & 20 & 20 & 20 \\
\hline$U_{1}(0)$ & 4 & 4 & 4 & 4 & 4 & 4 & 4 & 4 \\
$U_{2}(0)$ & -1 & -1 & -1 & -1 & -1 & -1 & -1 & -11 \\
$\partial U_{1}(0)$ & -0.95 & -0.85 & -0.75 & -0.65 & -0.55 & -0.45 & -0.35 & -0.25 \\
\hline$t_{0}$ & 30 & 20 & 11.4 & 11 & 8.4 & 6.3 & 4.5 & 3.0 \\
$t^{*}$ & 2.8 & 3.1 & 3.3 & 3.6 & 3.9 & 4.4 & 5.0 & 6.1 \\
\hline
\end{tabular}

The impact from gift reward can be found by examining $R$. We can write $R$ as $\lambda V(t)+R_{0}$. As a result, there is an adjustment from 2 to $2-\lambda$ in the coefficient of the $V(t)$ and an added constant in the function of $U_{1}-U_{2}$. However, this adjustment only creates small changes. If only $R$ increase, then $t_{1}$ decreases , $\left[U_{1}-U_{2}\right]\left(t_{1}\right)$ decreases and $t^{\star}$ decreases finally. And vice versa. The change in $T C_{1}$ and $T C_{2}$ also influences the value of $t^{\star}$ via changing the minimum of the function $\left[U_{1}-U_{2}\right](t)$. The integrated effect of $R+T C_{1}-T C_{2}$ can be shown in the table III.

TABLE III

Analysis of Decision Points of Various $R+T C_{1}-T C_{2}$

\begin{tabular}{ccccccccc}
\hline PAR & th2 & th3 & th3 & th & th5 & th6 & th7 & th7 \\
\hline $\mathrm{A}$ & 10 & 10 & 10 & 10 & 10 & 10 & 10 & 10 \\
$\mathrm{i}$ & 0.1 & 0.1 & 0.1 & 0.1 & 0.1 & 0.1 & 0.1 & 0.1 \\
$\mathrm{k}$ & 0.99 & 0.09 & 0.09 & 0.09 & 0.09 & 0.09 & 0.09 & 0.09 \\
$\mathrm{C}$ & 1 & 1 & 1 & 1 & 1 & 1 & 1 & 1 \\
$\mathrm{~s}$ & 0.1 & 0.1 & 0.1 & 0.1 & 0.1 & 0.1 & 0.1 & 0.1 \\
$\mathrm{R}$ & 5 & 5 & 5 & 5 & 5 & 5 & 4 & 6 \\
$T C_{1}$ & 1 & 2 & 3 & 4 & 1 & 1 & 1 & 1 \\
$T C_{2}$ & 2 & 2 & 2 & 2 & 1 & 3 & 2 & 2 \\
$\mathrm{~T}$ & 20 & 20 & 20 & 20 & 20 & 20 & 20 & 20 \\
\hline$U_{1}(0)$ & 9 & 8 & 7 & 6 & 9 & 9 & 9 & 9 \\
$U_{2}(0)$ & -7 & -7 & -7 & -7 & -6 & -8 & -8 & -6 \\
$\partial U_{1}(0)$ & -0.95 & -0.95 & -0.95 & -0.95 & -0.95 & -0.95 & -0.95 & -0.95 \\
\hline$t_{0}$ & 30 & 30 & 30 & 30 & 30 & 30 & 30 & 30 \\
$t^{*}$ & 15 & 13.1 & 11.5 & 10.1 & 13.1 & 17.4 & 17.4 & 13.1 \\
\hline
\end{tabular}

From above analysis, we can conclude that:

Theorem 9. The decrease in $S^{\prime}$ has the same effect with the increase in $R+T C_{1}-T C_{2}$, which would both cause the decrease in $t^{\star}$. Furthermore, inverse change in $R+T C_{1}-T C_{2}$ and $S^{\prime}$ would strengthen their effect while synchronized change in $R+T C_{1}-T C_{2}$ and $S^{\prime}$ would counteract their respective effects.

From the perspective of the owner of the good, the higher $S^{\prime}$ would bring higher income but the high income would discourage the owner to give the good as a gift according to our results. However, the high $S^{\prime}$ would also make the good less competitive at the same time. As the result of that, there is a equilibrium in the price setting for the sharer to obtain the maximum income and meanwhile it wouldn't eliminate the possibility for the gift giving.

From the perspective of government, to increase the reward by enhance the tax deduction is a good method to encourage people to give the good away as soon as possible. But it's impossible to promote the tax deduction without limiting cap, which is the most common current practice. As it can be seen from our results, the game between the sharing income and gift economy reward would play a key role in the owner's decision. Adjusting the tax deduction corresponding to the price of sharing market would make the reward more effective. 
From the perspective of firms that promote gift economy, normally these firms are considered nonprofit. There exist many challenges that they have to overcome, such as the lack of supply, the increasing demand of charity, the lack of understanding of both donors and receivers, and sometimes the financial difficulties to operate the platform and to reduce the transaction cost. Our result shows that by reducing the transaction cost, the time for people to give the good as gift would be brought forward, which means the platform would receive the goods earlier. Even for those who will not donate the goods, the reduced transaction cost and increased rewards would give them the motivation to donate. Our results also shows that today's ever booming sharing and resale economy, because of the reduced transaction cost to share and to resell along with increasing sharing and resale income thanks to the Internet, actually shrink the already small market size for the the gift economy. We prove that in order to boost the spirit of good-will in our society, the government and the charity organizations must come up with new models or effective taxation incentives to struggle with the increasing income of sharing or reselling in order to encourage the gift giving, like revising the tax deduction corresponding to the price of sharing market.

From the perspective of the sharing or reselling platform, reducing the transaction cost by new technology would help them receive more goods from the owner. And the goodwill for their efficiency like well distribution of the goods would attract more people to share or give their goods because they may believe that platform could help them fulfill their purpose. In that way, owing to the double-sided model, platform would benefit from the increasing sharer/donors by attracting more receivers, which would in turn promote the goodwill of platform. Nevertheless, transaction cost is the profit of platform, which means the transaction cost would not decease without limit. Compared with that in gift economy, our results shows that the difference between two kinds of transaction cost could be utilized by government or charity organizations to encourage people to give their good as a gift.

\section{Limitations \& Future Research}

In the paper, we assume that the sharing income is a linear function of time, which is the simplest form of income. However, the expression of sharing income actually is more complicated and probability problem should be taken into consideration because of the uncertainty in sharing market. As the result of that, we will consider combining other income function with the probability theory in order to get more accurate results in our future research. Moreover, reward of giving a gift could also become a variable instead of a constant, which would be an unprecedented work, so different models for reward would also be focused on in our future research. We expect that there exists a optimal model for reward and in that case, we could give a effective suggestion to the government and we hope our efforts could make sense in the future.

\section{Conclusion}

We consider the non-linear properties and boundaries in the three forms of sharing, gift, and resale economy. We decode the economic rationality and marketplace mechanisms in today's ever booming sharing/gifting/reselling networks. We contribute to the fundamental economics literature by decomposing a good into two parts: the ownership good and the detached good. The ownership good can be utilized or shared by the owner. The detached good can either be given as a gift or be resold for an income. The separation is bounded by considering the estimated finite life of the good and a future time stamp of detachment. We consider owner's holding cost, various transaction costs, rewards, as well as the incentive mechanism from the network. We find that there exist various conditions when certain ownership form is more preferred to the others. Our results also indicate that governmental and marketplaces' incentive policies play an important role when consumers make decisions among the three economic forms and consequently adjusting the total social welfare. To be more specific, we model both individual utility and the social welfare by considering sharing, gift, and resale to be substitutes. We show that the total social welfare can be increased by fine-tuning the incentives and the various adjustable transaction costs.

Thanks to the rapid development of various online social networks and recommender systems, today's consumers are able to gain access to information instantly, to communicate with another consumer conveniently, and to cut the cost of most c2c transactions by a great extent. The Internet has enabled the booming of the three emerging economic forms that we have discussed in this research. For future research, we foresee lots of variations and new economic modeling based on the research that we have presented in this research. For an instance, in reality the parameter of 
$k \leq \ln (1+i)$ in our model happens to appear more frequently than the ones when $k>\ln (1+i)$. However, the existing reward function loses its influence in the case of $k \leq \ln (1+i)$, which means an alternative reward mechanism should be designed.

\section{REFERENCES}

[1] Ausubel, Lawrence M., and Peter Cramton. "Vickrey auctions with reserve pricing." Assets, Beliefs, and Equilibria in Economic Dynamics. Springer Berlin Heidelberg, 2004. 355-367.

[2] Belk, R. (2014). You are what you can access: Sharing and collaborative consumption online. Journal of Business Research, 67(8), 1595-1600.

[3] Botsman, R., \& Rogers, R. (2011). What's mine is yours: how collaborative consumption is changing the way we live. London: Collins.

[4] Cheal, D. (2015). The gift economy. Routledge.

[5] Cohen, B., \& Kietzmann, J. (2014). Ride on! Mobility business models for the sharing economy. Organization \& Environment, 27(3), 279-296.

[6] Garratt, Rod, and Thomas Trotger. "Speculation in standard auctions with resale." Econometrica 74.3 (2006): 753-769.

[7] Hamari, J., Sjoklint, M., \& Ukkonen, A. (2015). The sharing economy: Why people participate in collaborative consumption. Journal of the Association for Information Science and Technology.

[8] Malhotra, A., \& Van Alstyne, M. (2014). The dark side of the sharing econoy and how to lighten it. Communications of the ACM, 57(11), 24-27.

[9] Marcoux, J. S. (2009). Escaping the gift economy. Journal of Consumer Research, 36(4), 671-685.

[10] Mas, Alexandre. "Labour unrest and the quality of production: Evidence from the construction equipment resale market." The review of economic studies 75.1 (2008): 229-258.

[11] Piramuthu, O. B., \& Zhou, W. (2016, January). Bicycle Sharing, Social Media, and Environmental Sustainability. In 2016 49th Hawaii International Conference on System Sciences (HICSS) (pp. 2078-2083). IEEE.

[12] Schor, J. (2014). Debating the sharing economy. Great transition initiative.

[13] Sundararajan, Arun. "From Zipcar to the sharing economy." Harvard Business Review 1 (2013).

[14] Zervas, G., Proserpio, D., \& Byers, J. (2015). The rise of the sharing economy: Estimating the impact of Airbnb on the hotel industry. Boston U. School of Management Research Paper, (2013-16). 